\title{
Immune promotive effect of bioactive peptides may be mediated by regulating the expression of SOCS1/miR-155
}

\author{
CAIXIA CHEN ${ }^{1}$, XIULAN SU ${ }^{1 *}$ and ZHIWEI HU ${ }^{1,2 *}$ \\ ${ }^{1}$ Clinical Medicine Research Center of The Affiliated Hospital, Inner Mongolia Medical University, \\ Hohhot, Inner Mongolia 010050, P.R. China; ${ }^{2}$ Department of Surgery, Division of Surgical Oncology, \\ James Comprehensive Cancer Center, The Ohio State University College of Medicine, Columbus, OH 43210, USA
}

Received September 22, 2018; Accepted April 26, 2019

DOI: $10.3892 /$ etm.2019.7734

\begin{abstract}
The present study was designed to evaluate the effect of bioactive hepatic peptide (BHP) on the immune function of mice and to examine the mechanism mediated by the related factors cytokine suppressor of cytokine signaling 1 (SOCS1) and microRNA (miR)-155. The mice were divided into eight groups, including a normal mouse group, normal peptide groups (low-dose, mid-dose and high-dose), an immunosuppressed group, and immunosuppressed with peptide groups (low-dose, mid-dose and high-dose). The proliferative ability of splenic lymphocytes was determined in vitro using a Cell Counting kit-8 assay. Wright's staining was used to assess the phagocytic function of macrophages. Histological changes in the spleen were evaluated by hematoxylin-eosin staining. The relevant factors SOCS1/miR-155 were assessed by immunohistochemistry and reverse transcription fluorescence-quantitative polymerase chain reaction analysis. The levels of the cytokines TGF- $\beta 1$, IL-10 and IL-17A were determined by enzyme-linked immunosorbent assay. First, the organ index, percentage of lymphocytes, phagocytosis experiments and splenic lymphocyte proliferation test results revealed that the immunodeficient mouse model had been successfully established. Second, compared with the control mice, the normal peptide group mice exhibited increased spleen and thymus indices, percentages of lymphocyte subsets, macrophage phagocytosis percentages, phagocytic indices, splenic lymphocyte proliferation and expression of $\mathrm{miR}-155$; however, the expression of SOCS1 was decreased in the normal peptide groups to
\end{abstract}

Correspondence to: Professor Xiulan $\mathrm{Su}$ or $\mathrm{Dr}$ Zhiwei Hu, Clinical Medicine Research Center of The Affiliated Hospital, Inner Mongolia Medical University, 1 Tongdao North Street, Hohhot, Inner Mongolia 010050, P.R. China

E-mail: xlsu@hotmail.com

E-mail: zhiwei.hu@osumc.edu

${ }^{*}$ Contributed equally

Key words: bioactive hepatic peptide, immune function, immunosuppression, health products varying extents. In addition, the expression of SOCS1 was upregulated, whereas that of miR-155 was downregulated in the immunosuppressed group. Compared with the mice in the immunosuppressed group, the mice in the immunosuppressed with peptide groups had increased spleen and thymus indices, percentages of lymphocyte subsets, macrophage phagocytosis percentages, phagocytic indices, splenic lymphocyte proliferation and expression of miR-155; however, the expression of SOCS1 was decreased in the immunosuppressed with peptide groups to varying extents. Following treatment with BHP, the secretion of TGF- $\beta 1$ in the spleen of the normal mice and immunosuppressed mice was significantly decreased, and the secretion of IL-10 was significantly increased. No significant difference in the expression of IL-17A was observed among the groups. In summary, BHP improved the immune function of the normal mice and immunosuppressed mice. This data provides a scientific basis for the development of bioactive peptide health products.

\section{Introduction}

MicroRNAs (miRNAs) are a recently identified group of small, single-stranded RNAs that do not encode proteins. The roles of miRNAs in the immune system have been investigated extensively. They are not only involved in innate immunity but also regulate adaptive immunity (1). Our previous study revealed that active peptides can perform biological functions by targeting certain miRNAs $(2,3)$. Therefore, it has been suggested that inhibiting or restoring the function of a miRNA can provide a therapeutic benefit in certain diseases $(4,5)$. However, this process requires an efficient and nontoxic miRNA delivery system. It has been reported that active peptides may also act as a delivery vector for miRNAs (6). In summary, in addition to targeting miRNAs, active peptides are also involved in the delivery of miRNAs, which are promising functional molecules. miRNA (miR)-155 was among the first miRNAs linked to immunity by virtue of its potent expression upregulation in multiple immune cell lineages, including $\mathrm{T}$ lymphocytes, B lymphocytes, macrophages and dendritic cells (7). In addition to the involvement of miR-155 in $\mathrm{T}$ lymphocyte activation, miR-155 can also be involved in $\mathrm{T}$ cell development, differentiation and responses $(8,9)$. Studies have shown that, in a miR-155-knockout mouse model, 
T cell-dependent antibody responses and cytokine production are reduced (10). In addition to being involved in T cell-related reactions, miR-155 is also involved in B lymphocyte-related reactions. Studies have shown that the high expression of the transcription factor PU.1 leads to B cell dysfunction, including loss of the production of IgG1 antibodies, TNF- $\alpha$ and lymphotoxin- $\alpha / \beta$ in miR-155-knockout animals (11). A high expression of miR-155 in $\mathrm{T}$ and $\mathrm{B}$ lymphocytes can mediate specific immunity and regulate the lymphocyte transcriptome and other biological functions, but can also mediate natural killer (NK) cell-associated nonspecific immunity (12). NK cells are a type of innate immune lymphocyte with anti-infection and antitumor effects (13). The molecular mechanism underlying NK cell activation remains to be fully elucidated. Following activation by cytokines, human and mouse NK cells significantly upregulate the expression of miR-155 (14). The mechanism by which miR-155 is regulated during NK cell activation is complex. miR-155 can set the threshold of activation and the degree of activation in mature NK cells, and it can be used as a dynamic regulator to regulate the activation of NK cells (14).

A wide variety of immunologically relevant target genes of miR-155 have been reported, and among these genes, suppressor of cytokine signaling 1 (SOCS1) can be targeted directly by miR-155 (15). SOCS is a type of inducible intracellular protein that serves important roles in immune and nonimmune functions. The SOCS family is now known to have eight member proteins, and SOCS1 and SOCS3 synergistically regulate the differentiation and response of $\mathrm{T}$ cells in the immune system (16). Whole lymphocyte transcriptome analysis has revealed that miRNAs serve a key role in lymphocyte subsets, including $\mathrm{B}$ lymphocytes and $\mathrm{CD}^{+}$and $\mathrm{CD}^{+} \mathrm{T}$ cells [including $\mathrm{T}$ helper $(\mathrm{Th}) 1, \mathrm{Th} 2$, Th17 cells and regulatory $\mathrm{T}$ (Treg) cells] (17). Th17 cells can secrete IL-17A to promote inflammation, and Treg cells can secrete IL-10 and TGF- $\beta 1$ to inhibit inflammation. Studies have shown that miR-155-knockout Treg cells cause increased expression of SOCS1. Researchers have speculated that miR-155 can promote the differentiation of Treg/Th17 cells by directly inhibiting SOCS1 and enhance the function of Th17 cells, which may be involved in the regulation of inflammatory diseases, at least partially through the regulation of SOCS1 $(18,19)$. The present study aimed to verify this hypothesis.

Bioactive peptides are a group of the most popular polypeptide proteins in current food research. They are peptide compounds that are beneficial to the life activities of living organisms or have physiological functions (20). These peptides are composed of several or tens of amino acids and are arranged in different ways. Their molecular weights are $<6,000 \mathrm{kDa}$, and these polypeptides have several biological functions, including hormonal effects, immune regulation, and antithrombotic, antihypertensive, cholesterol-lowering, antibacterial, antiviral and anticancer effects (21). Studies have confirmed that bioactive peptides are absorbed and utilized more readily than free amino acids (22). Modern biometabolism studies have found that the proteins ingested by humans are digested by various enzymes in the digestive tract; these digested proteins are not absorbed in the form of amino acids as previously suggested, but are absorbed more directly in the form of small peptides (composed of 2-15 amino acid residues), and dipeptides (composed of two amino acid residues) and tripeptides (composed of three amino acid residues) are absorbed more quickly than amino acids of the same composition (23). Bioactive peptides from animal and plant species are widely distributed. The active peptides used in the present study were derived from the liver of healthy goats. The peptides were prepared by Professor Su's research group at Inner Mongolia Medical University (Hohhot, China) using a bioengineering method. The extraction method has been established successfully, and the quality is controllable (24). Our previous studies have shown that these peptides can inhibit cancer cell growth, enhance cancer cell sensitivity to chemotherapeutic drugs and reduce toxic side effects on normal cells $(2,3)$.

The present study aimed to evaluate the effects of bioactive hepatic peptide (BHP) on the immune function of healthy mice and immunosuppressed mice and examine whether changes in the expression of SOCS1/miR-155 mediate the effects of $\mathrm{BHP}$ on mouse immune function. The results may provide a theoretical basis for the development of new health products.

\section{Materials and methods}

Preparation of $B H P$. Under relatively sterile conditions, the liver of two Boer goats (2-year-old females; Mengyang Animal Husbandry Co., Ltd.) was obtained and rapidly pulverized. The Boer goats were housed at $22-24^{\circ} \mathrm{C}$, with humidity at $45-50 \%$, good ventilation, and a natural light/dark cycle. The goats were given sufficient water four times a day and were fed four times a day (8:30 am, 12:30 am, 4:30 pm and 8:30 pm) with crude feed $1-1.25 \mathrm{~kg} /$ goat per day and fine feed $0.25 \mathrm{~kg} / \mathrm{goat}$. The mixture was homogenized with physiological saline at a ratio of 0.5-2 g/4 ml, frozen and thawed under low temperature conditions $\left(-80^{\circ} \mathrm{C}\right)$ three times, filtered, centrifuged $(14,000 \mathrm{x} \mathrm{g}$, $4^{\circ} \mathrm{C}, 20 \mathrm{~min}$ ), ultrafiltered and sterilized. The final filtrate was a pale yellow liquid, which was referred to as BHP solution. According to SDS-PAGE analysis, the molecular weight of the BHP was $\sim 8,000 \mathrm{kDa}(25)$. In addition, the concentration of the BHP solution was $42 \mathrm{mg} / \mathrm{ml}$. A BCA kit (Bradford) was used to determine the concentration of BHP at $450 \mathrm{~nm}$ on an enzyme label instrument.

Body weight and organ index determinations. A total of 40 male and 40 female Kunming mice (purchased from Beijing Weitong Lihua) with body weights of 18-22 g (6-8 weeks old) were housed for 5 days. The housing conditions were as follows: Indoor temperature, $18-22^{\circ} \mathrm{C}$; relative humidity, 50-70\%; 12/12 h light/dark cycles between 8:00 am-8:00 pm; free access to drinking water and food; and then randomly divided into eight groups of 10 mice. All animals were treated according to the protocol approved by the Institutional Animal Care and Use Committee (IACUC) of Inner Mongolia Medical University. The groups included the BHP (provided by the Clinical Research Center of the Affiliated Hospital of Inner Mongolia Medical University) high-dose group (100 mg/kg, HBHP), BHP mid-dose group (50 mg/kg, MBHP), BHP low-dose group (25 mg/kg, LBHP), cyclophosphamide (Cy)-treated immunosuppressed group (40 mg/kg Cy, Jiangsu Hengrui Pharmaceutical Co., Ltd.), Cy high-dose peptide group (40 mg/kg Cy, 100 mg/kg BHP; Cy + HBHP), Cy mid-dose peptide group (40 mg/kg Cy; $50 \mathrm{mg} / \mathrm{kg}$ BHP; Cy + MBHP), 
Cy low-dose peptide group (40 mg/kg Cy; $25 \mathrm{mg} / \mathrm{kg}$ BHP; $\mathrm{Cy}+\mathrm{LBHP}$ ), and a control group (intraperitoneal injection of the same volume of saline daily; Con). The mice in the immunosuppressed $\mathrm{Cy}$ combined with peptide groups were intraperitoneally injected with $\mathrm{Cy}$ three times (every other day) in advance. On day 4 , the remaining mice were administered with the appropriate dose of BHP twice daily, and the mice in the $\mathrm{Cy}$ groups were injected intraperitoneally every other day. During the administration period, the body weights were measured and recorded every 3 days at a fixed time point (9:00 a.m.). All mice were harvested 4 weeks later; the mice were sacrificed by cervical dislocation. The spleen and thymus gland were weighed under aseptic conditions, and the correlation indices were calculated according to following formulas: Spleen weight index $=$ spleen weight/body weight $\mathrm{x} 100$; and thymus index=thymus weight/body weight $x 100$.

Determination of lymphocyte percentages. Blood was collected from the posterior ocular vein following anesthetizing the mice with ether, and the mice were then sacrificed with carbon dioxide $\left(\mathrm{CO}_{2}\right)$ followed by cervical dislocation. Flow cytometry (BD Biosciences, Franklin Lakes, NJ, USA) was used to determine the total number of lymphocytes and the percentages of NK cells, and Th and killer or cytotoxic $\mathrm{T}$ cell $(\mathrm{Tc})$ lymphocytes. BD Multitest CD3/CD8/CD45/CD4 reagent and BD Multitest CD3/CD16+CD56/CD45/CD19 reagent were used for the lymphocyte percentage determinations. Various fluorescein-labeled monoclonal antibodies were added to the whole blood and combined with the corresponding antigens on the leukocytes. The blood was then subjected to hemolysis with 1X BD FACS Lysing Solution (cat. no. 349202; BD Biosciences) for $10 \mathrm{~min}$ at room temperature, fixation with $0.1 \%$ glutaraldehyde for $15 \mathrm{~min}$ at room temperature and washing with PBS, and was then analyzed with a flow cytometer. The percentages of the lymphocyte subsets were obtained. The fluorescein labeling and lymphocyte surface antigen distribution are shown in Table I. According to the differences in the $\mathrm{CD}$ molecule expression on lymphocyte membranes, flow cytometry can distinguish lymphocytes and their various subpopulations, and the percentages of lymphocyte subsets can be calculated with computer software. All procedures were performed according to the reagent instructions (BD Biosciences).

Determination of the phagocytic index. Three SPF chickens [8-week-old males reared at $27^{\circ} \mathrm{C}, 60 \%$ humidity and a $9 / 15 \mathrm{~h}$ light/dark cycle (light, 8:00 am-3:00 pm)] were fed six times a day with cold and white boiled water were purchased from the China Experimental Animal Information Network. All procedures were approved by the IACUC of Inner Mongolia Medical University. A blood collection needle (Beijing Haide Venture Biotechnology Co., Ltd.) and EDTA-K2 anticoagulation blood collection tube (Guangzhou Bangbiao Medical Instrument Co., Ltd.) were used for chicken wing vein blood collection. Blood was collected $(1 \mathrm{ml})$ and added to $2 \mathrm{ml}$ sterile saline followed by centrifugation at $1,760 \mathrm{x}$ f for $10 \mathrm{~min}$ at room temperature. The supernatant was discarded, and the blood cells were suspended in physiological saline, following which the precipitate was centrifuged in the same manner as above. The red blood cells were washed three times, and the
$0.05 \%$ chicken red cell suspension was prepared using sterile physiological saline. At 12:00 p.m. on day 27, the mice were injected intraperitoneally with $1 \mathrm{ml}$ of preprepared $0.5 \%$ starch solution, and fasted with water overnight. At 6:00 a.m. on day 28 , each mouse was injected with $0.05 \%$ chicken red blood cells prepared in advance, and the abdomen of the mice was then gently massaged to disperse the chicken red blood cells. The mice were anesthetized at 12:00 p.m. on day 28 and sacrificed with $\mathrm{CO}_{2}$ asphyxiation, followed by cervical dislocation. The abdominal cavity of the mice was washed with $1 \mathrm{ml}$ of physiological saline, and $\sim 0.5 \mathrm{ml}$ of peritoneal lavage fluid was sampled and stained $1 \mathrm{~h}$ at $37^{\circ} \mathrm{C}$ with Wright's staining reagent (Beijing Solarbio Science \& Technology Co., Ltd., CAS: 68988-92-1, reagent no. G1040). Wright's staining is commonly used for staining blood (mainly white blood cells and red blood cells) and bone marrow smears during biochemical research (26-28). The number of phagocytic cells engulfing the chicken erythrocytes and the number of chicken erythrocytes phagocytosed by 100 phagocytic cells were counted under an oil-immersion objective (Olympus Corporation, Tokyo, Japan) and calculated according to following formulas: Percentage of phagocytosis $(\%)=$ number of macrophages that engulfed chicken red blood cells/100 phagocytes $\mathrm{x} 100$; and phagocytosis index=number of chicken erythrocytes engulfed/100 phagocytes $x 100$.

Determination of lymphocyte proliferation. A spleen cell suspension was prepared and counted under a microscope (Olympus Corporation), and the cell density was adjusted to $2 \times 10^{5} / \mathrm{ml}$ for use. A total of $100 \mu \mathrm{l}$ of spleen cell suspension was added to each well of a 96 -well flat-bottomed culture plate. The final concentration of concanavalin A (ConA; Nanjing Jinyibai Biotechnology Co., Ltd.) was $7.5 \mu \mathrm{g} / \mu \mathrm{l}$, and $100 \mu \mathrm{l}$ of RPMI 1640 medium (Gibco, Thermo Fisher Scientific, Inc.) was added to the control wells. Three repetitions were performed in parallel for the experimental and control wells. The culture plate was placed in a $37^{\circ} \mathrm{C}, 5 \% \mathrm{CO}_{2}$ incubator and incubated for $66 \mathrm{~h}$. The state of the cells was observed once a day. The plate was removed and $20 \mu 1$ of CCK-8 (Dojindo Institute of Japan) was added to each well and incubated for a further $2.5 \mathrm{~h}$. Following incubation, the absorbance (A) was measured with a microplate reader (Molecular Devices, LLC) at a wavelength of $450 \mathrm{~nm}$. The splenic lymphocyte proliferation rate and stimulation index were calculated according to the following formulas: Proliferation rate $=\left(\mathrm{A}_{\mathrm{ConA}}-\mathrm{A}_{\mathrm{RPMI1640}}\right) / \mathrm{A}_{\mathrm{RPMI1640}}$; and stimulus index $=\mathrm{A}_{\text {ConA }} / \mathrm{A}_{\mathrm{RPMI}}$ 640 .

$H \& E$ staining. Excised specimens were fixed with $4 \%$ paraformaldehyde (Linyi URB Chemical Co., Ltd.), dehydrated and embedded in paraffin. H\&E staining was performed on 4- $\mu \mathrm{m}$-thick paraffin sections containing a representative, well-preserved splenic tissue sample. The sections were examined under a light microscope at x100 and x400 magnification. The slides of all treatment groups were examined and images were captured.

Determination of the expression of miR-155 in the mouse spleen. RNA extraction was performed using TRIzol reagent (CWBio Beijing Kangwei Century Biotechnology Co., Ltd.). The reverse transcription primers (Sangon Biotech Co., Ltd., Shanghai, 
Table I. Determination of lymphocyte percentage.

\begin{tabular}{|c|c|c|c|}
\hline Kit & Contents & Lymphocyte subset & CD molecules \\
\hline BD Multitest CD3/CD8/CD45/CD4 reagent & $\begin{array}{l}\text { FITC-labeled CD3, } \\
\text { PE-labeled CD8, } \\
\text { PerCP-labeled CD45, } \\
\text { APC-labeled CD4 }\end{array}$ & $\begin{array}{l}\text { Lymphocyte } \\
\text { T helper cell } \\
\text { Cytotoxic T cell }\end{array}$ & $\begin{array}{l}\mathrm{CD} 45^{+} \\
\mathrm{CD}^{+}, \mathrm{CD}^{+}, \mathrm{CD} 45^{+} \\
\mathrm{CD}^{+}, \mathrm{CD}^{+}, \mathrm{CD}^{+} 5^{+}\end{array}$ \\
\hline BD Multitest CD3/CD16+CD56/CD45/CD19 reagent & $\begin{array}{l}\text { FITC-labeled CD3, } \\
\text { PE-labeled CD16, } \\
\text { PE-labeled CD56, } \\
\text { PerCP-labeled CD45, } \\
\text { APC-labeled CD19 }\end{array}$ & $\begin{array}{l}\text { B lymphocyte } \\
\text { Natural killer cell }\end{array}$ & $\begin{array}{l}\mathrm{CD} 3^{-}, \mathrm{CD} 19^{+}, \mathrm{CD}_{4} 5^{+} \\
\mathrm{CD}^{-}, \mathrm{CD}^{+} 6^{+}, \mathrm{CD}^{+} 5^{+}\end{array}$ \\
\hline
\end{tabular}

$\mathrm{CD}$, cluster of differentiation; PE, phycoerythrin; PerCP, peridinin chlorophyll; APC, allophycocyanin.

China) were as follows: miR-155, 5'-GCACTTCAGTGTCGT GGTCAGTGACGGCAATTTGAAGTGCACCCCTAT-3' and U6, 5'-CGCTTCACGAATTTGCGTGTCAT-3'. The RT reaction mixture was included in the PrimeScript 1st Strand cDNA Synthesis kit (Thermo Fisher Scientific, Inc.). All procedures followed the manufacturer's instructions. Samples were incubated at $25^{\circ} \mathrm{C}$ for $5 \mathrm{~min}, 42^{\circ} \mathrm{C}$ for $60 \mathrm{~min}, 70^{\circ} \mathrm{C}$ for $5 \mathrm{~min}$ and then maintained at $4^{\circ} \mathrm{C}$. When the instrument was at $4^{\circ} \mathrm{C}$, the cDNA was removed and stored in a $-86^{\circ} \mathrm{C}$ freezer. Real-time fluorescence quantitative polymerase chain reaction (qPCR) analysis was used to determine the level of miR-155. The RT-qPCR protocol was as previously described by Ji et al (29). The sequences of the primers used (Sangon Biotech Co., Ltd., Shanghai, China) were as follows: miR-155 forward: 5'-CAGACGACCATCAGTTAA TGCTAATTGTGAT-3', miR-155 reverse: 5'-CGTCGTCAC TGACCACGACACTG-3', U6 forward: 5'-GCTTCGGCAGCA CATATACTAAAAT-3' and U6 reverse: 5'-CGCTTCACGAAT TTGCGTGTCAT-3'. Applied Biosystems ${ }^{\mathrm{TM}}$ SYBR $^{\mathrm{TM}}$ Green mix (Thermo Fisher Scientific, Inc.) was used, and all procedures were performed following the manufacturer's instructions. PCR was performed with the ABI 7500 Real-Time PCR system (Applied Biosystems; Thermo Fisher Scientific, Inc.) The quantification of PCR results was performed using the $2^{-\Delta \Delta C q}$ method, as described by Ji et al (29).

Immunohistochemical detection of the expression of SOCS1 in the mouse spleen. The excised specimens were fixed with 4\% paraformaldehyde (Linyi URB Chemical Co., Ltd.) at room temperature for a week, dehydrated (70, 80, 90 and $100 \%$ alcohol for 5 min per gradient) and embedded in paraffin. A standard immunohistochemical staining procedure was performed using $4-\mu \mathrm{m}$-thick paraffin sections containing a representative, well-preserved splenic tissue sample, as recommended by the primary antibody supplier. Tissues were rehydrated in decreasing concentrations of graded ethanol and double distilled water. Endogenous peroxidase/phosphatase activity was blocked with $3 \%$ hydrogen peroxide for $10 \mathrm{~min}$ at room temperature. Non-specific expression was blocked with ready-to-use normal goat serum (cat. no. AR0009; Boster Biotechnology Co., Ltd.) at room temperature for $10 \mathrm{~min}$. SOCS1 antigens were retrieved by heating at high pressure in a pressure cooker with $1 \mathrm{mmol} / \mathrm{l}$ EDTA $(\mathrm{pH} 8.0)$ for $7 \mathrm{~min}$ at a temperature of $98^{\circ} \mathrm{C}$ at $90 \mathrm{kPa}$. Sections were incubated with anti-SOCS1 primary antibodies (cat. no. PA5-27239; dilution of 1:500; Invitrogen; Thermo Fisher Scientific, Inc.) at $37^{\circ} \mathrm{C}$ for $2 \mathrm{~h}$, rinsed three times ( $3 \mathrm{~min} /$ time) with PBS, and incubated with horseradish peroxidase-conjugated goat anti-rabbit immunoglobulin G secondary antibodies (cat. no. G21234; dilution of 1:1,000; Invitrogen; Thermo Fisher Scientific, Inc.) for $10 \mathrm{~min}$ at room temperature. The sections were washed with PBS three times (3 min/time), then incubated with 3,3'-diaminobenzidine for $5 \mathrm{~min}$ at room temperature. Tissues were counterstained with hematoxylin for $5 \mathrm{~min}$ at room temperature, and dehydrated in increasing concentrations of graded ethanol and xylene. Staining intensity for SOCS1 expression was assessed under an optical microscope. The method of scoring immunohistochemical staining was as described by Zhang et al (30); the cell staining density and the staining intensity under an optical microscope at a magnification of $\mathrm{x} 100$ were used to establish the semi-quantitative scoring method for the immunohistochemical results. The positive cell density scoring method was as follows: 0 , no positive cells; $1,1-10 \%$ positive cells; $2,10-50 \%$ positive cells; $3,50-80 \%$ positive cells; and 4, $80-100 \%$ positive cells. The color intensity of the positive cells was scored as follows: 0 , negative; 1, light color (light brownish yellow); 2 , moderate coloring (brown); and 3, strong staining (dark brownish yellow). The product of the color density and the intensity was used as the final score result.

Determination of the levels of cytokines $I L-17 A, I L-10$ and $T G F-\beta 1$. The splenic tissue was stored in a $-86^{\circ} \mathrm{C}$ freezer. The levels of IL-10, IL-17A and TGF- $\beta 1$ in the splenic tissues were determined using commercial enzyme-linked immunosorbent assay (ELISA) kits (Wuhan Xinqidi Biological Technology Co., Ltd.) according to the manufacturer's protocols. All samples were tested in triplicate.

Statistical analysis. Statistical analysis was performed using SPSS version 23.0 (IBM, Corp.). Each experiment was performed at least in triplicate. One-way analysis of variance was used. Significant differences among the treatment means were determined at a 5\% confidence level using Duncan's Multiple Range test. 


\section{Results}

Successful establishment of an immunosuppressed mouse model. Compared with the mice in the Con group, there were no significant differences in body weight among the groups (Fig. 1A). However, an upward trend was observed when comparing the $\mathrm{Cy}$ group with groups treated with $\mathrm{Cy}$ and increasing doses of BHP. In addition, the spleen and thymus indices of the Cy group were significantly decreased (Fig. 1B and C). The percentage of total lymphocytes, Tc cell percentage, Th cell percentage and phagocytosis index of mice in the Cy group were significantly decreased compared with those of mice in the Con group (Fig. 2A-D). The level of phagocytosis by peritoneal macrophages in mice of the $\mathrm{Cy}$ group was also significantly lower than that of mice in the Con group (Fig. 3A-C). Although there was no significant difference in the proliferation of splenic lymphocytes from the mice in vitro, there was a downward trend in the $\mathrm{Cy}$ group (Fig. 4A and B). Therefore, the immunosuppressed mouse model was considered to be successfully established. The $H \& E$ results showed that the splenic tissue samples from the Cy group, the LBHP + Cy group, the MBHP + Cy group and the HBHP + Cy group all exhibited abnormalities to varying degrees (Fig. 5). Lymphocytes were sparse, and the splenic structure was ambiguous and irregularly arranged. The number of lymphocytes was decreased, red veins were engorged with small veins, the splenic sinus was marginally expanded, and lymphoid follicles and necrotic cells were visible in the Cy groups compared with the Con group. The Cy group exhibited the most marked changes, which indicated that $\mathrm{Cy}$ had a certain damaging effect on the mouse spleen. In summary, establishment of the immunosuppressed mouse model was successful.

BHP improves immunity in normal mice. Compared with those of mice in the Con group, the body weights of mice in the LBHP, MBHP and HBHP groups were increased in a dose-dependent manner, although there were no significant differences. In addition, the spleen and thymus indices of mice in the LBHP, MBHP and HBHP groups were significantly increased (Fig. 1B and C). The percentage of total lymphocytes, NK cell percentage, Tc cell percentage and Th cell percentage in the HBHP group were significantly increased compared with those in the Con group (Fig. 2A-D). These percentages increased in a dose-dependent manner; however, there were no significant differences between the LBHP group and the MBHP group (Fig. 2A-D). Furthermore, the phagocytosis percentage and phagocytic index of macrophages from the mice were significantly increased in the LBHP, MBHP and HBHP groups (Fig. 3A-C). The proliferation rate and proliferation index of the splenocytes from the mice in the MBHP and HBHP groups were significantly increased in vitro (Fig. 4A and B). The H\&E staining result shows no obvious changes in morphology among the LBHP, MBHP and HBHP groups (Fig. 5). This indicates that HBP can improve immunity in normal mice and does not cause damage to the spleen morphology.

BHP improves immunity in immunosuppressed mice. Compared with $\mathrm{Cy}$ mice, the body weights of mice in the
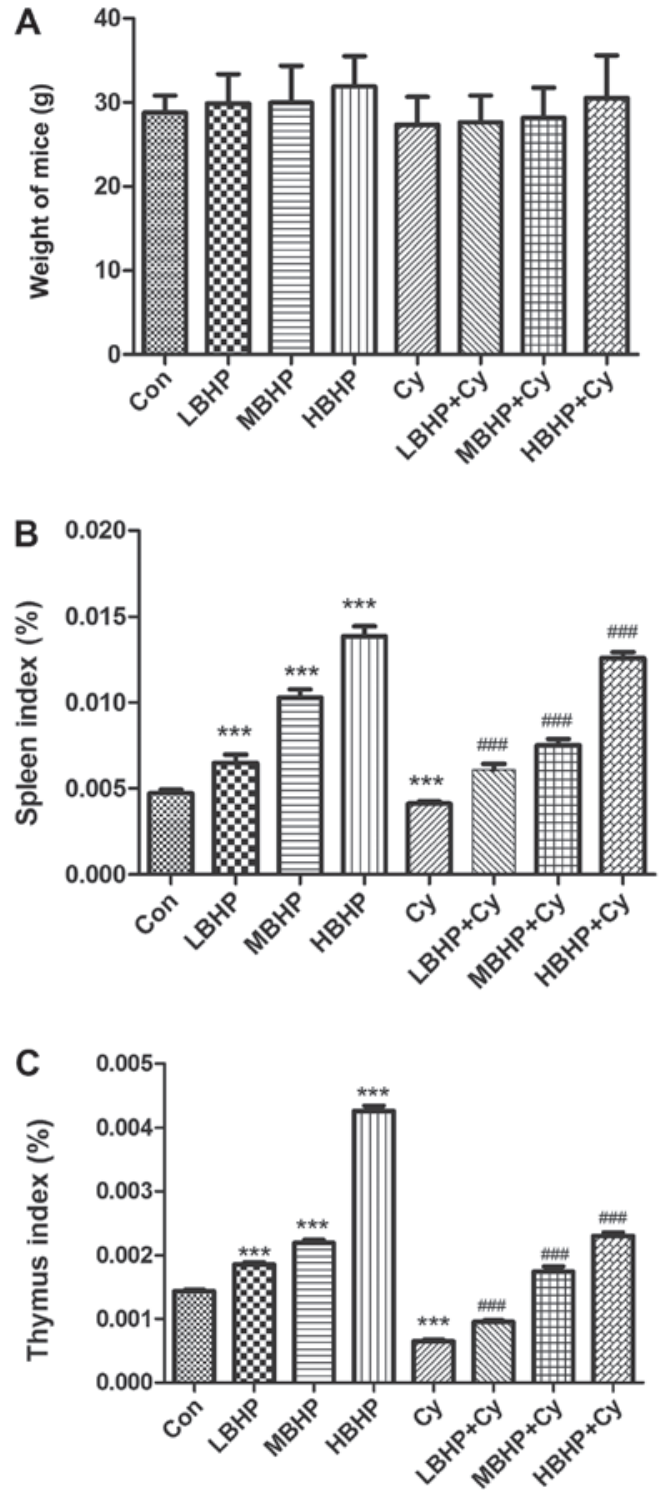

Figure 1. Weight, spleen index and thymus index of normal untreated mice and normal and immunosuppressed mice treated with BHP. (A) Weights of mice. There was an increased trend in the BHP group, although no significant differences between groups were observed. (B) Spleen index of the mice. Significant differences were observed when comparing the Cy, LBHP, MBHP or HBHP group with the Con group. Significant increases were observed in the $\mathrm{LBHP}+\mathrm{Cy}, \mathrm{MBHP}+\mathrm{Cy}$ and $\mathrm{HBHP}+\mathrm{Cy}$ groups compared with the $\mathrm{Cy}$ group. (C) Thymus index of the mice. Significant differences were observed when comparing the Cy, LBHP, MBHP or HBHP group with the Con group. Significant differences were observed when comparing the $\mathrm{LBHP}+\mathrm{Cy}$, $\mathrm{MBHP}+\mathrm{Cy}$ or HBHP + Cy group with the Cy group. ${ }^{* * *} \mathrm{P}<0.0001$ vs. Con group; ${ }^{\# \# \#} \mathrm{P}<0.0001$ vs. Cy group. All data were from two independent experiments, each of which was repeated in parallel twice. BHP, bioactive hepatic peptide; LBHP, low-dose BHP; MBHP, mid-dose BHP; HBHP, high-dose BHP; Cy, cyclophosphamide; Con, control.

$\mathrm{LBHP}+\mathrm{Cy}$ group, MBHP + Cy group and HBHP + Cy group increased in a dose-dependent manner, although differences were not significant (Fig. 1A). However, the spleen and thymus indices of mice in the LBHP + Cy group, $\mathrm{MBHP}+\mathrm{Cy}$ group and $\mathrm{HBHP}+\mathrm{Cy}$ group were significantly increased (Fig. 1B and C). The percentage of total lymphocytes, NK cell percentage, Tc cell percentage and Th cell percentage in the MBHP $+\mathrm{Cy}$ group and $\mathrm{HBHP}+\mathrm{Cy}$ group were significantly increased compared with those in the $\mathrm{Cy}$ 

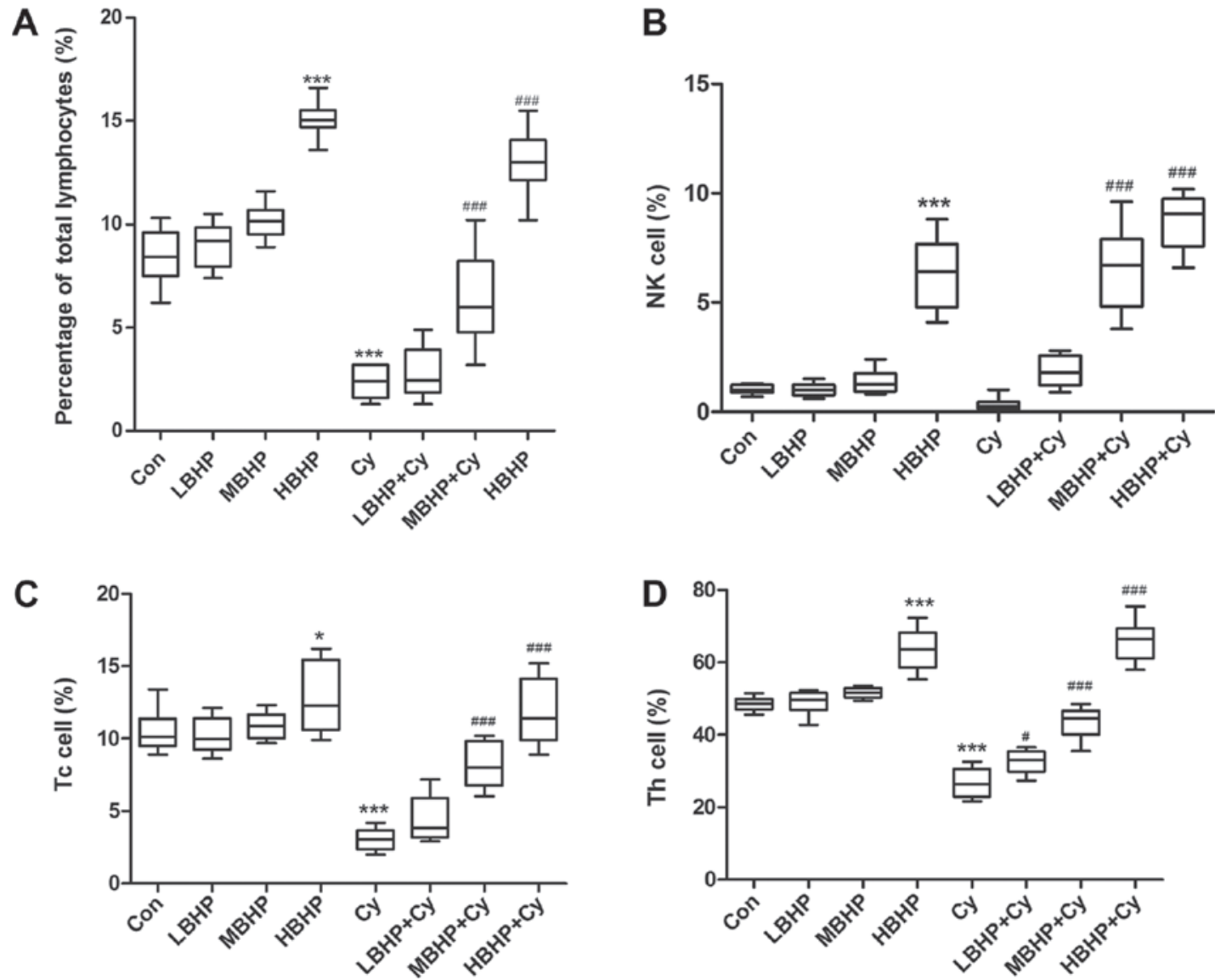

Figure 2. Percentages of lymphocytes in normal untreated mice and normal and immunosuppressed mice treated with BHP. (A) Percentages of total lymphocytes were increased in the HBHP group and significantly decreased in the Cy group compared with that in the Con group, and were increased significantly in the MBHP + Cy and HBHP + Cy groups compared with that in the Cy group. (B) Percentages of NK cells. NK cell percentage was increased significantly in the HBHP group compared with that in the Con group. NK cell percentages were increased significantly in the MBHP + Cy and HBHP + Cy groups compared with that in the Cy group. (C) Percentages of Tc cells. Tc cell percentage was increased in the HBHP group and significantly decreased in the Cy group compared with that in the Con group. Percentages of Tc cells were increased significantly in the MBHP + Cy and HBHP + Cy groups compared with that in the Cy group. (D) Percentage of Th cells was increased in the HBHP group and significantly decreased in the Cy group compared with that in the Con group. Percentages of Th cells were increased significantly in the LBHP + Cy, MBHP + Cy and HBHP + Cy groups compared with that in the Cy group. "P<0.01 vs. Con group; ${ }^{* * * * *} \mathrm{P}<0.0001$ vs. Con group; ${ }^{\# \mathrm{P}}<0.01$ vs. Cy group; ${ }^{\# \# \#} \mathrm{P}<0.0001$ vs. Cy group. All data were from two independent experiments, each of which was repeated in parallel twice. BHP, bioactive hepatic peptide; LBHP, low-dose BHP; MBHP, mid-dose BHP; HBHP, high-dose BHP; Cy, cyclophosphamide; Con, control; NK, natural killer; Tc, cytotoxic T cell; Th, T helper cell.

group (Fig. 2A-D). In addition, the percentage of macrophage phagocytosis and phagocytic index of macrophages were increased significantly in mice in the MBHP + Cy group and HBHP + Cy group, and the former was also increased significantly in the LBHP + Cy group (Fig. 3A-C). The proliferation rate and proliferation index of splenic cells from mice in MBHP $+\mathrm{Cy}$ group and $\mathrm{HBHP}+\mathrm{Cy}$ group were increased significantly in vitro (Fig. $4 \mathrm{~A}$ and $\mathrm{B}$ ). The $\mathrm{H} \& \mathrm{E}$ staining result showed relatively neatly arranged lymphocytes and relatively intact cell structure in the LBHP $+\mathrm{Cy}$, $\mathrm{MBHP}+\mathrm{Cy}$ and HBHP $+\mathrm{Cy}$ groups compared with the Cy group, but no pathological inflammatory lesions were found, which indicated that BHP can effectively protect against the splenic tissue damage caused by immunosuppressive agents (Fig. 5).

miR-155/SOCS1 mediates the regulation of immune function in mice induced by BHP. The relative expression of miR-155 was upregulated in the LBHP, MBHP and HBHP groups but decreased in the Cy group compared with that in the Con group
(Fig. 6). In addition, the expression of miR-155 was increased in the MBHP + Cy group and the HBHP + Cy group compared with that in the Cy group to a certain degree. The expression of SOCS1 was downregulated in the groups of mice treated with LBHP, MBHP or HBHP but increased in the Cy group compared with that in the Con group (Fig. 7). In addition, the expression of SOCS1 was decreased in the LBHP $+\mathrm{Cy}$, $\mathrm{MBHP}+\mathrm{Cy}$ and HBHP + Cy groups compared with that in the Cy group. Therefore, the expression of miR-155/SOCS1 may mediate the regulation of immune function in mice induced by BHP.

TGF- $\beta 1$ and IL-10, but not IL-17A, are involved in the regulation of immune function in mice induced by $B H P$. Following treatment with BHP, the secretion of TGF- $\beta 1$ in the spleen of the normal mice and immunosuppressed mice was significantly decreased (Fig. 8A), and the level of IL-10 secretion was significantly increased (Fig. 8B). No significant difference in the level of IL-17A was observed among the groups (Fig. 8C). 
A
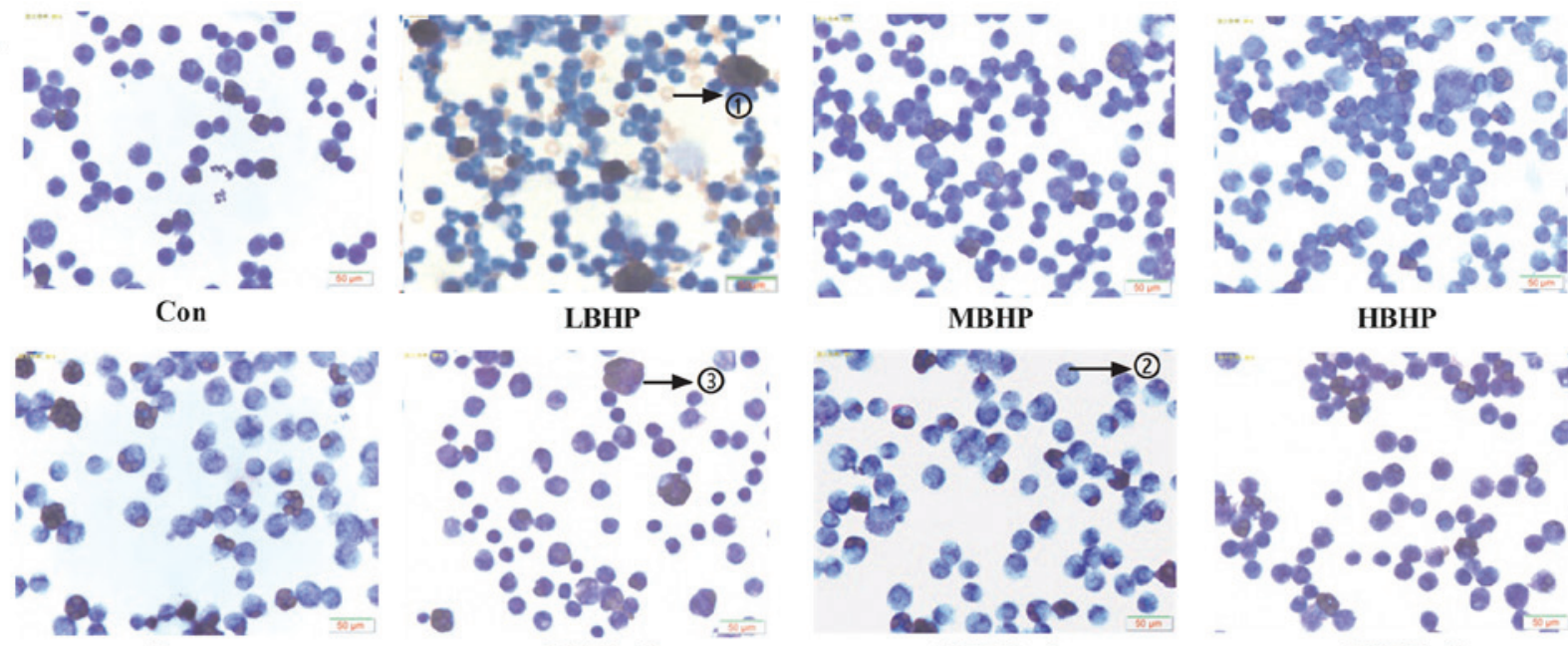

LBHP

Cy
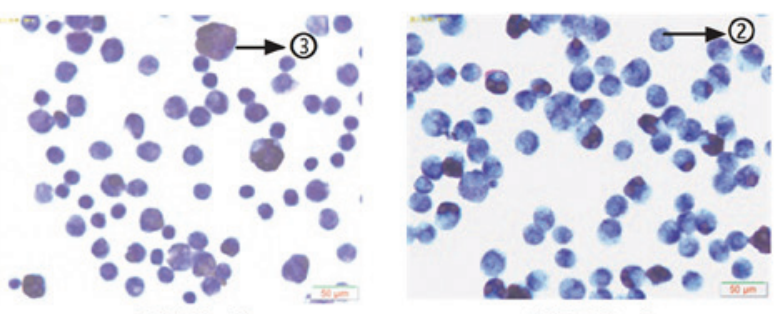

$\mathrm{MBHP}+\mathrm{Cy}$

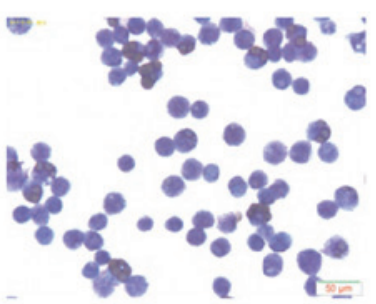

$\mathrm{LBHP+Cy}$

B

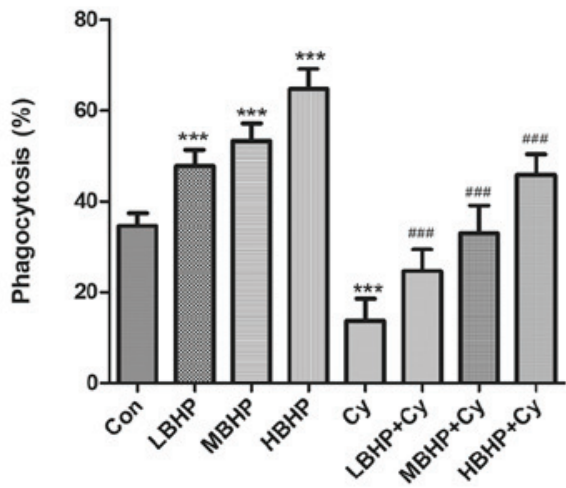

C

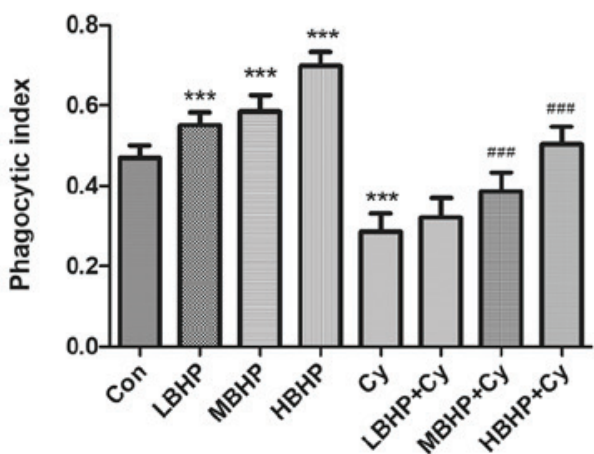

Figure 3. Macrophage phagocytosis in normal untreated mice and normal and immunosuppressed mice treated with BHP. (A) Wright's staining results (x400 magnification with a light microscope). Due to the pre-injection of starch, as a non-self-contained substance, such stimulation can produce more macrophages. Numerous macrophages, macrophages that have engulfed chicken red blood cells, and a small number of unphagocytosed chicken red blood cells were observed under oil microscope. The numbers on the images represent the following: 1) unphagocytosed chicken red blood cells; 2) macrophages that have not engulfed chicken red blood cells, and 3) macrophages that had engulfed chicken red blood cells. (B) Percentage of phagocytosis. Phagocytosis was increased significantly in the LBHP, MBHP and HBHP groups and decreased significantly in the Cy group compared with that in the Con group. Phagocytosis was increased significantly in the LBHP + Cy, MBHP + Cy and HBHP + Cy groups compared with that in the Cy group. (C) Phagocytic index. The index was increased significantly in the LBHP, MBHP and HBHP groups and decreased significantly in the Cy group compared with that in the Con group. The index

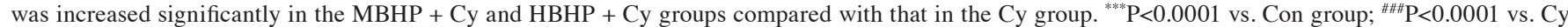
group. All data were from two independent experiments, each of which was repeated in parallel twice. BHP, bioactive hepatic peptide; LBHP, low-dose BHP; MBHP, mid-dose BHP; HBHP, high-dose BHP; Cy, cyclophosphamide.

\section{Discussion}

The immune system, which is mainly composed of immune organs, immune cells and immunologically active substances, is important in immune surveillance, defense and regulation. The spleen is the largest immune organ and the thymus is the main immune organ. Therefore, the spleen index and thymus index are generally used to measure immune function (31). According to the results of the present study, the spleen index and thymus index of the mice treated with BHP were significantly higher than those of the mice in the normal control group $(\mathrm{P}<0.01)$, and there was a correlation between the intensity of the spleen index and the dose of BHP.

$\mathrm{T}$ lymphocytes and B lymphocytes are derived from pluripotent stem cells in the bone marrow. The lymphoid stem cells that differentiate from pluripotent stem cells can migrate in the blood, move to the thymus gland and mature within the thymus; therefore, these cells are termed thymus-dependent lymphocytes or T lymphocytes. Bone marrow cells that mature in the bone marrow are known as bone marrow-dependent lymphocytes, which are B lymphocytes (32). T and B lymphocytes stimulated by an antigen or mitogen in vitro can be converted into larger, metabolically competent, mitotic lymphoblasts (33). ConA can stimulate the conversion and proliferation of $\mathrm{T}$ lymphocytes. The degree of $\mathrm{T}$ cell transformation and proliferation can reflect the cellular immune function of the body. A previous study also showed that lipopolysaccharides can stimulate the transformation of B lymphocytes, reflecting humoral immunity in the body (34). The spleen is the largest peripheral lymphoid organ in the body and is the site where $\mathrm{T}$ and $\mathrm{B}$ lymphocytes reside. T lymphocytes account for $\sim 35 \%$ of the splenocyte population, and B lymphocytes account for $\sim 55 \%$. Therefore, the level of lymphocyte activity in the spleen represents its immune function ability (35). In the present study, ConA was used as a stimulus for the transformation and proliferation of splenic $\mathrm{T}$ lymphocytes in each experimental mouse. The stimulation index and proliferation rate of the lymphocytes in 

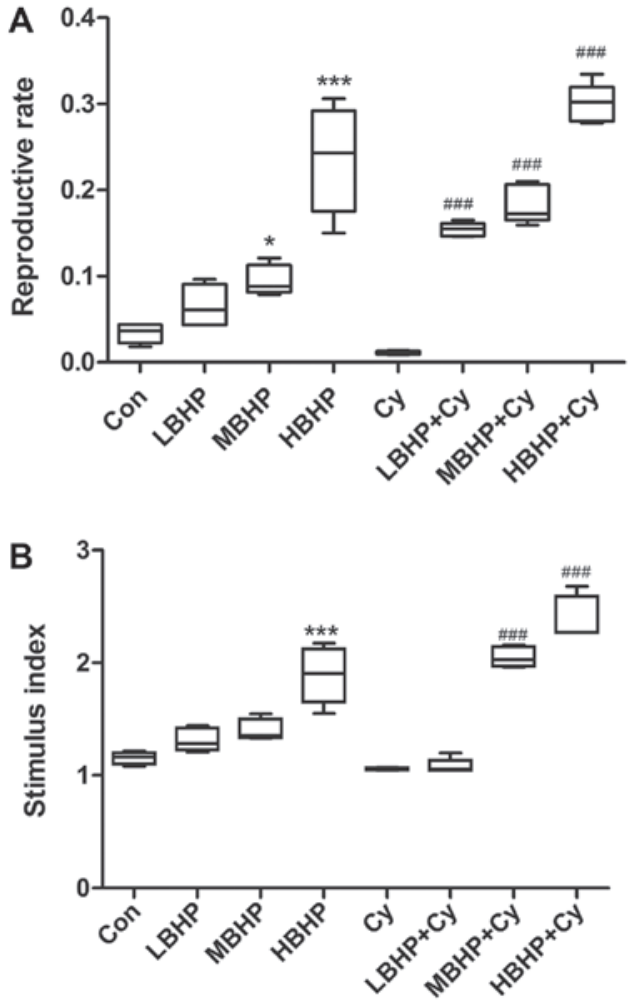

Figure 4. In vitro proliferation of splenic lymphocytes from normal untreated mice and normal and immunosuppressed mice treated with BHP. (A) Proliferation rate. Proliferation was increased significantly in the MBHP and HBHP groups compared with that in the Con group, and increased significantly in the LBHP + Cy, MBHP + Cy and HBHP + Cy groups compared with that in the Cy group. (B) Stimulus index. The index was significantly increased in the HBHP group compared with that in the Con group, and significantly increased in the MBHP + Cy and HBHP + Cy groups compared with that in the Cy group. $\mathrm{P}<0.01$ vs. Con group; ${ }^{* * *} \mathrm{P}<0.0001$ vs. Con group

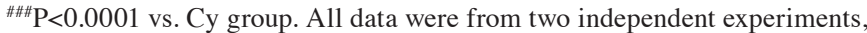
each of which was repeated in parallel twice. BHP, bioactive hepatic peptide; LBHP, low-dose BHP; MBHP, mid-dose BHP; HBHP, high-dose BHP; Cy, cyclophosphamide.

the splenic tissues of each experimental group were measured using a microplate reader. The results showed that the in vitro proliferation rate and proliferation index of the splenocytes from mice in the HBHP group were increased significantly compared with those from mice in the Con group $(\mathrm{P}<0.0001)$, and similar results in the immunosuppressed BHP treatment group indicated that BHP effectively promoted the transformation ability of splenic lymphocytes. These results indicate that BHP can enhance splenic lymphocyte proliferation in normal mice and immunosuppressed mice and are consistent with the findings of Yu et al (36). T cells are the main lymphocytes and have a variety of biological functions. $\mathrm{T}$ cells can be divided into three subgroups, adjuvant or induced T cells (Th), Tc and suppressor $\mathrm{T}$ cells (37). Th cells are $\mathrm{CD} 4^{+} \mathrm{T}$ lymphocytes, which express CD4 on the cell surface. These cells are activated by recognizing polypeptide antigens presented by major histocompatibility complex (MHC)II. MHCII is expressed on the surface of antigen-presenting cells (APCs). Cytokines can be secreted by APCs and are secreted by T cells following activation. Lymphokines promote the differentiation of $\mathrm{B}$ cells into effector B cells, thereby modulating or assisting the immune response (38). Tc cells are $\mathrm{CD}^{+} \mathrm{T}$ lymphocytes that express CD8 on the cell surface; CD8 can bind directly to an antigen through $\mathrm{MHCI}$, leading to the release of perforin. The killing of target cells by factors including perforin and granzymes, and the initiation of target cell apoptosis also explain why these cells are referred to as cytotoxic cells (39). In the present study, the percentage of Th lymphocytes and the percentage of Tc lymphocytes were determined. The results showed that the percentage of Th lymphocytes in the HBHP group was significantly increased compared with that in the Con group $(\mathrm{P}<0.0001)$. The percentages of Tc lymphocytes in the LBHP group and the MBHP group were increased compared with that in the control group, although the difference was not significant. The percentage of Tc lymphocytes in the HBHP group was increased significantly $(\mathrm{P}<0.01)$. The percentages of Th lymphocytes in the LBHP + Cy group $(\mathrm{P}<0.01)$, the MBHP $+\mathrm{Cy}$ group and the HBHP $+\mathrm{Cy}$ group $(\mathrm{P}<0.0001)$ were significantly increased compared with that in the Cy group, and these increases were correlated with the BHP dose. These findings indicate that BHP can increase the numbers of Th lymphocytes and Tc cells in normal mice and immunosuppressed mice to a certain extent. These findings are similar to the results of previous studies (40-42).

NK cells are known as natural killer cells due to their killing activity, which is not MHC restricted and is independent of antibodies. Although it is generally considered that NK cells are derived from the bone marrow, there is currently no definite evidence to explain their source. NK cells are mainly distributed in the peripheral blood, therefore, venous blood from the mouse eye was used in the present study. NK cells can nonspecifically recognize target cells and exert their killing effect through perforin, NK cytotoxic factor and TNF (43). When NK cells are activated, they can secrete various cytokines, thereby contributing to physiological functions, including antiviral infection responses, immune surveillance and the killing of mutant tumor cells (44). NK cells are granular lymphocytes and important immune cells. Therefore, the number of NK cells is an important indicator of immune function. In the present study, mouse immune cells were evaluated by measuring the percentage of mouse NK cells. The results showed that, compared with that in the Con group, the percentage of NK cells in the HBHP group was significantly increased $(\mathrm{P}<0.0001)$ and the percentages in the mice treated with MBHP $+\mathrm{Cy}$ or HBHP $+\mathrm{Cy}$ were significantly increased $(\mathrm{P}<0.0001)$ compared with that in mice in the immunosuppressed model group. The increase was correlated with the BHP dose. These results show that BHP can increase the number of NK cells in normal and immunosuppressed mice.

The types of immunity comprise mainly nonspecific immunity and specific immunity, and the latter is divided into cellular immunity and humoral immunity. Nonspecific immunity, also known as innate immunity, refers to the natural ability of the body to establish protection and includes the barrier function of the mucosal system and the phagocytosis of foreign bodies by phagocytic cells. Innate immunity is the basis of adaptive immunity, and immune substances produced by adaptive immune system components can enhance the role of the innate immune system (45). Macrophages, which are nonspecific immune cells derived from the proliferation and differentiation of leukocytes, 


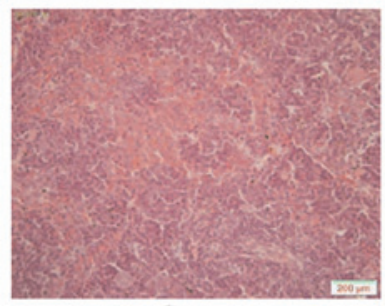

Con

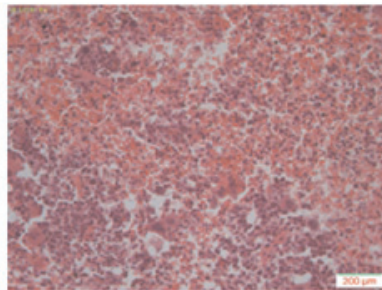

Cy

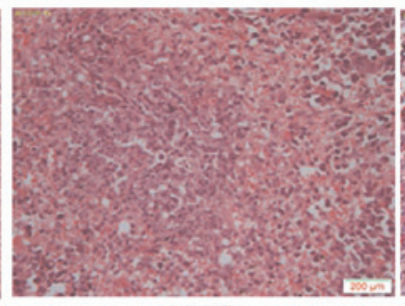

LBHP

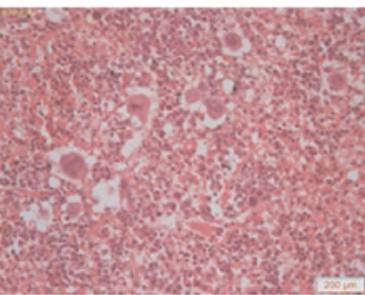

$\mathrm{LBHP}+\mathrm{Cy}$

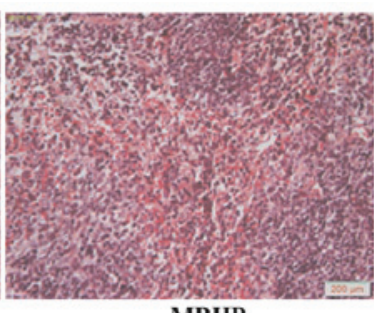

MBHP

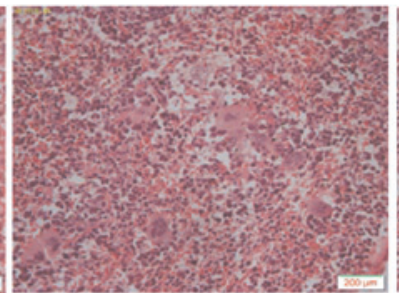

$\mathrm{MBHP}+\mathrm{Cy}$

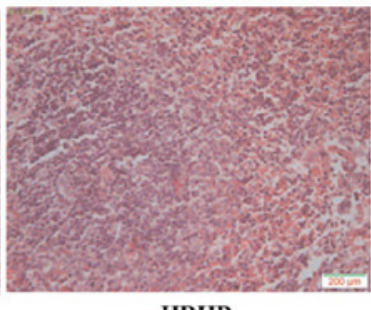

HBHP

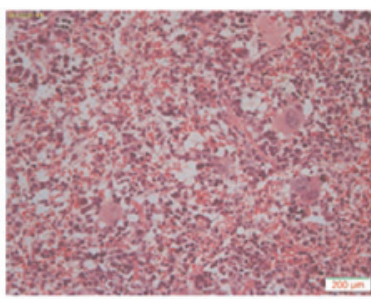

$\mathrm{HBHP}+\mathrm{Cy}$

Figure 5. Hematoxylin-eosin staining of the mouse spleen. Images were captured at x100 magnification with a light microscope. The spleen of the mice in the Cy group, LBHP + Cy group, MBHP + Cy group and HBHP + Cy group all exhibited abnormalities to varying degrees compared with that in the Con group. The lymphocyte arrangement was sparse, and the structure was ambiguous and irregularly arranged. The number of lymphocytes was decreased, red veins were engorged with small veins, the splenic sinus was marginally expanded, and lymphoid follicles and necrotic cells were visible. The Cy group exhibited the most marked changes. No substantial changes were found among the LBHP group, MBHP group and HBHP group. The LBHP + Cy group, $\mathrm{MBHP}+\mathrm{Cy}$ group and HBHP + Cy group had relatively neatly arranged lymphocytes and relatively clear cell structure. All data were from two independent experiments, each of which was repeated in parallel twice. BHP, bioactive hepatic peptide; LBHP, low-dose BHP; MBHP, mid-dose BHP; HBHP, high-dose BHP; Cy, cyclophosphamide.

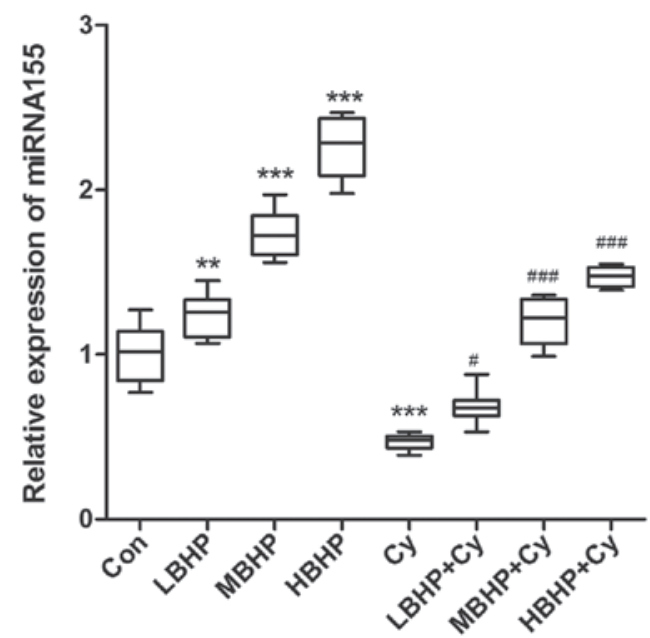

Figure 6. Relative expression of miR-155 in the spleen of untreated normal mice and normal and immunosuppressed mice treated with BHP. Expression was increased significantly in the LBHP, MBHP and HBHP groups and decreased significantly in the Cy group compared with that in the Con group. Expression was increased significantly in the LBHP $+\mathrm{Cy}$, $\mathrm{MBHP}+\mathrm{Cy}$ and HBHP $+\mathrm{Cy}$ groups compared with that in the Cy group ${ }^{* *} \mathrm{P}<0.001$ vs. Con group, ${ }^{* * *} \mathrm{P}<0.0001$ vs. Con group; ${ }^{*} \mathrm{P}<0.01$ vs. Cy group, ${ }^{\# \# \# \#} \mathrm{P}<0.0001$ vs. Cy group. All data were from two independent experiments, each of which was repeated in parallel twice. BHP, bioactive hepatic peptide; LBHP, low-dose BHP; MBHP, mid-dose BHP; HBHP, high-dose BHP Cy, cyclophosphamide; miR/miRNA, microRNA.

are the most important phagocytes in the immune system. They are responsible for phagocytosing, processing and treating antigenic substances, transmitting antigens to lymphocytes and stimulating lymphocytes to produce antibodies or lymphokines to enhance the ability to kill target cells. In turn, the production of antibodies and lymphokines also enhances macrophage chemotaxis, activation and phagocytosis (46). Therefore, the phagocytic ability of macrophages is directly related to the strength of immune function. In the present study, macrophage phagocytosis was evaluated by measuring the phagocytic index and the percentage of phagocytosis in each experimental group of mice to evaluate changes in immune function. The results showed that the percentage of phagocytosing macrophages and the phagocytic index in the LBHP, MBHP and HBHP groups were significantly increased compared with those in the control group $(\mathrm{P}<0.0001)$. Additionally, the percentage of phagocytosing macrophages and the phagocytic index of mice in the LBHP $+\mathrm{Cy}, \mathrm{MBHP}+\mathrm{Cy}$ and $\mathrm{HBHP}+\mathrm{Cy}$ groups were significantly increased compared with those of the mice in the immunosuppressed model group, and the intensity of these effects was correlated with the BHP dose $(\mathrm{P}<0.0001)$, indicating that BHP can increase the phagocytic ability of macrophages in normal mice and immunosuppressed mice. These findings are similar to those of Yu et al (36).

Additionally, Cy is a member of the class of alkylating agents widely used for the treatment of cancer. It mainly exerts its killing mechanism by interfering with DNA and RNA synthesis in cells. As with most chemotherapeutics, it kills tumor cells and a certain proportion of normal cells. This killing effect, particularly in the thymus, spleen and other immune organs, is potent and can reduce lymphocyte antibody production, resulting in low immune function (47). To assess this feature in the present study, mice were treated with an intraperitoneal injection of $40 \mathrm{mg} / \mathrm{kg}$ Cy every other day, which led to varying degrees of weight loss. The immune organ indices also decreased to a certain extent, and the percentage of lymphocytes was relatively low in the $\mathrm{Cy}$ group compared with that in the normal control group. These results are consistent with those in the literature, indicating the modeling was successful (48). 


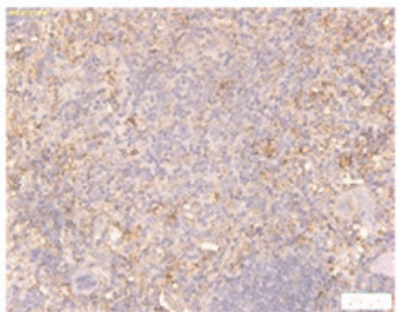

Con

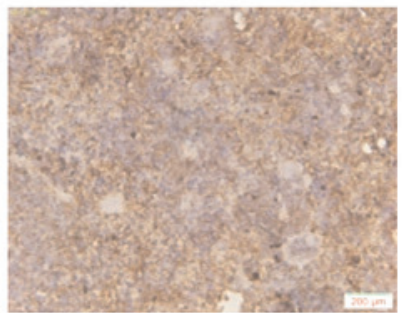

Cy

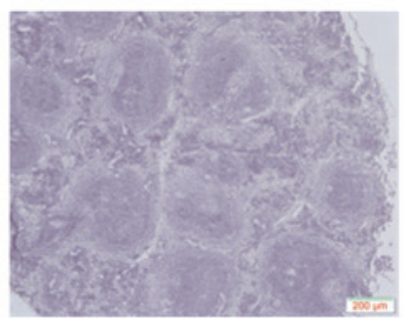

Negative control

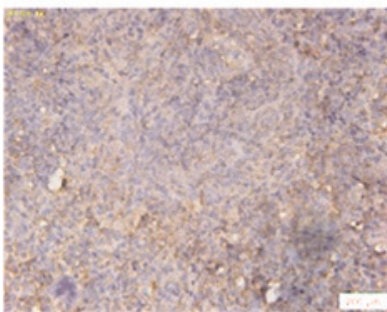

LBHP

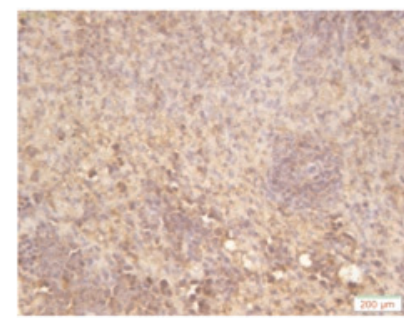

LBHP+Cy

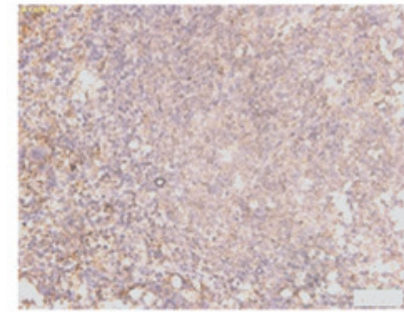

MBHP

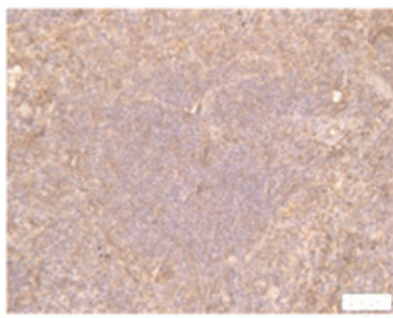

$\mathbf{M B H P}+\mathbf{C y}$

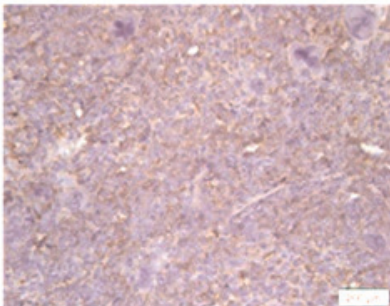

HBHP

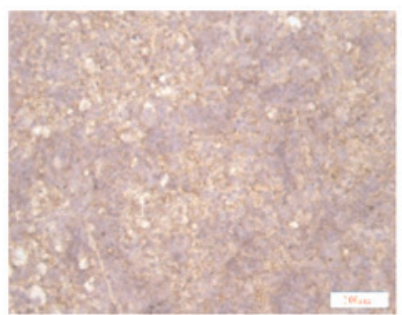

$\mathrm{HBHP}+\mathrm{Cy}$

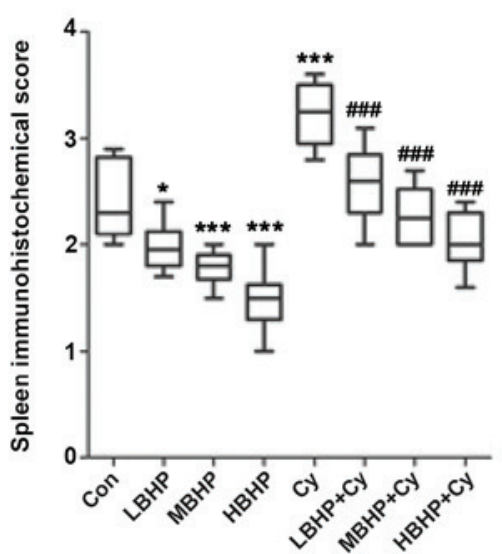

Figure 7. Expression of SOCS1 in the spleen of untreated normal mice and normal and immunosuppressed mice treated with BHP. Expression was decreased significantly in the LBHP, MBHP and HBHP groups, and increased significantly in the Cy group compared with that in the Con group. Expression was decreased significantly in the LBHP $+\mathrm{Cy}, \mathrm{MBHP}+\mathrm{Cy}$ and HBHP $+\mathrm{Cy}$ groups compared with that in the Cy group. ${ }^{*} \mathrm{P}<0.01$ vs. Con group; ${ }^{* * *} \mathrm{P}<0.0001$ vs. Con group, ${ }^{\# \#} \mathrm{P}<0.0001$ vs. Cy group. All data were from two independent experiments, each of which was repeated in parallel twice. BHP, bioactive hepatic peptide; LBHP, low-dose BHP; MBHP, mid-dose BHP; HBHP, high-dose BHP; Cy, cyclophosphamide; SOCS1, suppressor of cytokine signaling 1.
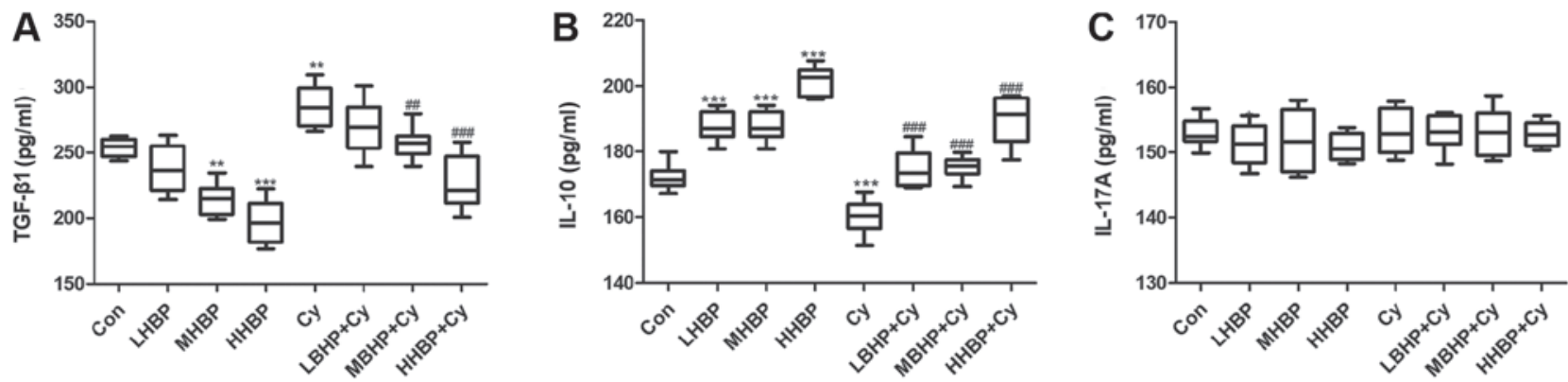

Figure 8. Secreted levels of TGF- $\beta 1$, IL-10 and IL-17A in the spleen of mice. (A) Secreted levels of TGF- $\beta 1$ were downregulated significantly in the MBHP and HBHP groups and upregulated significantly in the Cy group compared with that in the Con group. Levels were decreased significantly in the MBHP + Cy and HBHP + Cy groups compared with that in the Cy group. (B) Secreted levels of IL-10 were upregulated significantly in the LBHP, MBHP and HBHP groups and downregulated significantly in the Cy group compared with that in the Con group. Levels were increased significantly in the LBHP $+\mathrm{Cy}, \mathrm{MBHP}+\mathrm{Cy}$ and HBHP + Cy groups compared with that in the Cy group. (C) No significant differences in the expression of IL-17A were found among groups. *" $\mathrm{P}<0.001$ and ${ }_{* * * *} \mathrm{P}<0.0001$ vs. Con group; ${ }^{\# \#} \mathrm{P}<0.001$ and ${ }^{\# \# \#} \mathrm{P}<0.0001$ vs. Cy group. All data were from two independent experiments, each of which was repeated in parallel three times.

The results of the present study also showed that the expression of miR-155 was significantly upregulated in the MBHP and HBHP groups compared with that in the
Con group $(\mathrm{P}<0.0001)$. The expression of miR-155 was also significantly higher in the LBHP group $(\mathrm{P}<0.01)$, $\mathrm{LBHP}+\mathrm{Cy}$ group $(\mathrm{P}<0.001), \mathrm{MBHP}+\mathrm{Cy}$ group and 
HBHP + Cy group $(\mathrm{P}<0.0001)$ compared with that in the Cy group $(\mathrm{P}<0.0001)$. The expression of SOCS1 was significantly downregulated in the LBHP group, MBHP group and HBHP group compared with that in the Con group. Compared with the Cy group, significantly downregulated expression of SOCS1 was observed in the MBHP and HBHP + Cy groups $(\mathrm{P}<0.0001)$. These results indicate that the expression of miR-155/SOCS1 may mediate the regulation of immune function in mice induced by BHP. These results are consistent with the results of other studies on miR-155/SOCS1 (49-52).

Finally, TGF- $\beta 1$ is mainly secreted by activated T and B lymphocytes and macrophages, and is mainly produced by lymphocytes. TGF- $\beta 1$ is involved not only in the development of the thymus but also in the maturation of $\mathrm{T}$ cells (53). TGF- $\beta 1$ is a multifunctional cytokine that affects a variety of biological processes, including inflammation, cell differentiation and immune responses (54). IL-10 is primarily derived from monocytes, macrophages and Th cells. In addition, dendritic cells (DCs), B cells, mast cells, Tc cells, NK cells, eosinophils and neutrophils secrete IL-10 (55). IL-10 has a dual role in regulating the immune system, as it can promote B cell proliferation, differentiation and antibody production but can also inhibit inflammation $(56,57)$. Activated Th17 cells can secrete IL-17A, which is an inflammatory factor that promotes inflammatory responses. In the present study, the secretion of IL-10 in the mouse spleen was significantly increased following BHP treatment in the normal mice and the immunosuppressed mice, and this finding indicates that IL-10 mediates the BHP-induced regulation of immune function in mice. IL-10 has a positive role in regulating immune function in mice. However, the majority of studies have focused on the negative regulatory role of IL-10, and even consider it and TGF- $\beta 1$ to be immunosuppressive factors secreted by Treg cells (58). The results of the present study showed that the levels of TGF- $\beta 1$ in the spleen of normal and immunosuppressed mice were significantly decreased following BHP treatment, indicating that TGF- $\beta 1$ mediates the BHP-induced regulation of immune function in mice. In addition, TGF- $\beta 1$ has a negative regulatory role in the immune function of mice. The results of the present study are similar to those reported previously (59). IL-17A is a recognized inflammatory factor, and there was no significance difference in IL-17A levels among the groups. Therefore, it was possible to conclude that the establishment of the immunosuppressed model with Cy did not cause splenic inflammation in mice, and this finding is consistent with the H\&E staining results. In addition, if BHP mediates the maintenance of the Treg/Th17 balance, IL-10 and TGF- $\beta 1$ would act as immunosuppressive factors simultaneously, however, the results of the present study overturn this conjecture. In addition, others have shown that miR-155 can downregulate the level of TGF- $\beta 1$ (60). The results of the present study appear to show similar trends, although further experiments are required to verify these findings. Therefore, BHP regulates the immune function in mice but not by improving inflammation. BHP has a regulatory role in the immune system of mice by upregulating the expression of immune-stimulating factors (including IL-10) or downregulating the expression of certain immunosuppressive factors (including TGF- $\beta 1$ ) and ultimately achieves the effect of improving immune function.

However, there are certain limitations to the present study, including insufficient fresh blood samples for Treg/Th17 cell ratio determination and insufficient tissue specimens for further experiments, including western blot analysis. In addition, the BHP used in the present study was only compared with the traditional immunosuppressive drug $(\mathrm{Cy})$, whereas the classic immune protection drug Transfer Factor Oral Solution (Jinhua, Xi'an, China) was used in our subsequent experiments (unpublished data). The present study was performed in normal mice and immunosuppressive model mice; further experiments are required on the immunosuppressive mouse model based on the tumor mouse model, and related tumor cell lines require verification. The regulatory mechanism of BHP on immune function also requires further investigation.

In conclusion, data from in vivo and in vitro experiments in the present study show that BHP can significantly improve immune function in healthy and immunosuppressed mice, suggesting that the development of BHP into a healthcare product suitable for healthy individuals or chemotherapy-treated cancer patients has an optimistic future. However, further large-sample basic research and preclinical validation studies are required. In addition, the relative expression of SOCS1/miR-155 and the secreted levels of TGF- $\beta 1$ and IL-10 are regulated by BHP, which means that BHP has the potential to improve immunity as a health supplement. A limitation of this study is that it discusses BHP preliminarily at the molecular level. The next step is to investigate whether the intestinal flora affects the BHP-mediated regulation of immune function.

\section{Acknowledgements}

Not applicable.

\section{Funding}

This study was supported by grants from the National Natural Science Foundation of China (grant nos. 81450047 and 81660468) and Inner Mongolia Autonomous Region Higher Education Research Project of China (grant no. NJZY19106).

\section{Availability of data and materials}

All data generated or analyzed during this study are included in this published article.

\section{Authors' contributions}

CC performed the experiments and wrote the manuscript. XS designed the study, and drew and edited the figure. ZH analyzed the experimental data. All authors read and approved the final manuscript.

\section{Ethics approval and consent to participate}

All animals were treated according to the protocol approved by the Institutional Animal Care and Use Committee of Inner Mongolia Medical University. 


\section{Patient consent for publication}

Not applicable.

\section{Competing interests}

The authors declare that they have no competing interests.

\section{References}

1. McKenzie CG, Guo L, Freedman J and Semple JW: Cellular immune disfunction inimmune thrombocytopenia (ITP). Br J Haematol 163: 10-23, 2013

2. Xing Z, Yu L, Li X and Su X: Anticancer bioactive peptide-3 inhibits human gastric cancer growth by targeting miR-338-5p Cell Biosci 6: 53, 2016

3. Su X, Dong C, Zhang J, Su L, Wang X, Cui H and Chen Z: Combination therapy of anti-cancer bioactive peptide with Cisplatin decreases chemotherapy dosing and toxicity to improve the quality of life in xenograft nude mice bears human gastric cancer. Cell Biosci 4: 7-19, 2014.

4. Słotwiński R, Lech G and Słotwińska SM: Therapeutic microRNAs in human cancer. Cent Eur J Immunol 43: 314-324, 2018.

5. Prabahar A and Natarajan J: ImmunemiR-A database of prioritized immune miRNA disease associations and its interactome. Microrna 6: 71-78, 2017.

6. Zhang Y, Köllmer M, Buhrman JS, Tang MY and Gemeinhart RA Arginine-rich, cell penetrating peptide-anti-microRNA complexes decrease glioblastoma migration potential. Peptides 58: 83-90, 2014.

7. Xiao C and Rajewsky K: MicroRNA control in the immune system: Basic principles. Cell 136: 26-36, 2009.

8. Escobar T, Yu CR, Muljo SA and Egwuagu CE: STAT3 activates miR-155 in Th17 cells and acts in concert to promote experimental autoimmune uveitis. Invest Ophthalmol Vis Sci 54: 4017-4025, 2013

9. Preston GC, Sinclair LV, Kaskar A, Hukelmann JL, Navarro MN, Ferrero I, MacDonald HR, Cowling VH and Cantrell DA: Single cell tuning of Myc expression by antigen receptor signal strength and interleukin-2 in T lymphocytes. EMBO J 34: 2008-2024, 2015.

10. Sobhkhez M, Joensen LL, Tollersrud LG, Strandskog G, Thim HL and Jørgensen JB: A conserved inhibitory role of suppressor of cytokine signaling 1 (SOCS1) in salmon antiviral immunity. Dev Comp Immunol 67: 66-76, 2017.

11. Ma C, Wang Y, Shen A and Cai W: Resveratrol upregulates SOCS1 production by lipopolysaccharide-stimulated RAW264.7 macrophages by inhibiting miR-155. Int J Mol Med 39: 231-237, 2017.

12. Yokoyama WM, Kim S and French AR: The dynamic life of natural killer cells. Annu Rev Immunol 22: 405-429, 2004.

13. Vivier E, Tomasello E, Baratin M, Walzer T and Ugolini S: Functions of natural killer cells. Nat Immunol 9: 503-510, 2008.

14. Sullivan RP, Fogel LA, Leong JW, Schneider SE, Wong R, Romee R, Thai TH, Sexl V, Matkovich SJ, Dorn GW II, et al: miR-155 tunes both the threshold and extent of NK cell activation via targeting of multiple signaling pathways. J Immunol 191: 5904-5913, 2013

15. Lu LF, Thai TH, Calado DP, Chaudhry A, Kubo M, Tanaka K, Loeb GB, Lee H, Yoshimura A, Rajewsky K and Rudensky AY: Foxp3-dependent microRNA155 confers competitive fitness to regulatory $\mathrm{T}$ cells by targeting SOCS1 protein. Immunity 30 80-91, 2009.

16. Banerjee A, Schambach F, DeJong CS, Hammond SM and Reiner SL: Micro-RNA-155 inhibits IFN-gamma signaling in CD4+ T cells. Eur J Immunol 40: 225-231, 2010

17. Okoye IS, Czieso S, Ktistaki E, Roderick K, Coomes SM, Pelly VS, Kannan Y, Perez-Lloret J, Zhao JL, Baltimore D, et al: Transcriptomics identifieda critical role for Th2 cell-intrinsic miR-155 in mediating allergy andantihelminth immunity. Proc Natl Acad Sci USA 111: E3081-E3090, 2014.

18. Yao R, Ma YL, Liang W, Li HH, Ma ZJ, Yu X and Liao YH MicroRNA-155 modulates treg and Th17 cells differentiation and Th17 cell function by targeting SOCS1. PLoS One 7: e46082, 2012.
19. Yan L, Hu F, Yan X, Wei Y, Ma W, Wang Y, Lu S and Wang Z: Inhibition of microRNA-155 ameliorates experimental autoimmune myocarditis by modulating Th17/Treg immune response. J Mol Med (Berl) 94: 1063-1079, 2016.

20. Babicz-Zielinska E and Jezewska-Zychowicz M: Conceptual model of consumer's willingness to eat functional foods. Rocz Panstw Zakl Hig 68: 33-41, 2017.

21. Bose U, Hodson MP, Shaw PN, Fuerst JA and Hewavitharana AK : Two peptide, cycloaspeptide A and nazumamide A from a sponge associated marine actinobacterium Salinispora sp. Nat Prod Commun 9: 545-546, 2014.

22. Pessione $\mathrm{E}$ and Cirrincione S: Bioactive molecules released in food by lactic acid bacteria: Encrypted peptides and biogenic amines. Front Microbiol 7: 876, 2016.

23. Silk DB, Grimble GK and Rees RG: Protein digestion and amino acid and peptide absorption. Proc Nutr Soc 44: 63-72, 1985.

24. Su X, Chen C, Liu Q, She Y, Yan M and Hou J: Preparation method of anti-gastric cancer bioactive peptide. China Patent ZL96122236.0, Filed November 4, 1996; issued September 4, 2000.

25. Li L, Yu L, Hu J, et al: Establishment of separation and identification methods for bioactive peptide protein components. Sheng Wu Ji Shu Tong Xun 25: 682-686, 2014.

26. Crago SS, Prince SJ, Pretlow TG, McGhee JR and Mestecky J: Human colostral cells. I. Separation and characterization. Am J Clin Exp Immunol 38: 585-597, 1979.

27. Shen QC, Lin Y, Wang SY, et al: Identification and culture of Buffalo peripheral blood mononuclear macrophage. China Animal Husbandry \& Veterinary Medicine 38: 31-35, 2011

28. Stevenson HC, Katz P, Wright DG, Contreras TJ, Jemionek JF, Hartwig VM, Flor WJ and Fauci AS: Human blood monocytes: Characterization of negatively selected human monocytes and their suspension cell culture derivatives. Scand J Immunol 14: 243-256, 1981

29. Ji H, Tian D, Zhang B, Zhang Y, Yan D and Wu S: Overexpression of miR-155 in clear-cell renal cell carcinoma and its oncogenic effect through targeting FOXO3a. Exp Ther Med 13: 2286-2292, 2017.

30. Zhang SP, Wang W, Gu Y, Jin L and Zhou F: Study on the correlation between ultrasonic imaging features in breast cancer and the expression of ER, PR, HER-2 and nm23. Biomedical Res 28: 5925-5929, 2017.

31. Ke M, Wang H, Zhou Y, Li J, Liu Y, Zhang M, Dou J, Xi T, Shen B and Zhou C: SEP enhanced the antitumor activity of 5 -fluorouracil by up-regulating NKG2D/MICA and reversedimmune suppressionvia inhibiting ROS and caspase-3 in mice. Oncotarget 7: 49509-49526, 2016.

32. Zhou G, Wang D, Liu D, Qi D and Liu Z: Expression of B and $\mathrm{T}$ lymphocyte attenuator in patients with severe community-acquired pneumonia and the effect of steroid therapy in a mouse model. Clin Lab 62: 2367-2377, 2016.

33. Pavić I, Katalinić-Janković V, Čepin-Bogović J, Rešić A and Dodig S: Discordance between tuberculin skin test and interferon- $\gamma$ release assay in children younger than 5 years who have been vaccinated with bacillus calmette-guérin. Lab Medicine 46: 200-206, 2015.

34. Janossy G, Snajdr J and Simakellis M: Patterns of B-lymphocyte gene expression elicited by lipopolysaccharide mitogen. Immunology 30: 799-810, 1976.

35. Smialek M, Tykalowski B, Dziewulska D, Stenzel T and Koncicki A: Immunological aspects of the efficiency of protectotype vaccination strategy against chicken infectious bronchitis. BMC Vet Res 13: 1-44, 2017.

36. Yu Y, Wang H, Meng X, Hao L, Fu Y, Fang L, Shen D, Yu X and Li J: Immunomodulatory effects of cinobufagin on murine lymphocytes and macrophages. Evid Based Complement Alternat Med 2015: 835263, 2015.

37. Bernard M, Furlong SJ, Power Coombs MR and Hoskin DW: Differential inhibition of T lymphocyte proliferation and cytokine synthesis by [6]-Gingerol, [8]-Gingerol, and [10]-Gingerol. Phytother Res 29: 1707-1713, 2015.

38. Nicholson LB: The immune system. Essays Biochem 60: 275-301, 2016.

39. Tsai CY, Allie SR, Zhang W and Usherwood EJ: MicroRNA miR-155 affects antiviral effector and effector memoryCD8 T cell differentiation. J Virol 87: 2348-2351, 2013.

40. Shi J, Bo S and Miao M: Effect of Astragalus polysaccharide on immunological function of immunosuppressive mice induced by cyclophosphamide. Zhong Yi Xue Bao 31: 243-246, 2016.

41. Cai K, Wang X, Zhang B, et al: Effects of Curculigo chinensis polysaccharides on immune function in immunosuppressed mice induced by cyclophosphamide. Zhong Hua Zhong Yi Yao Za Zhi 148-152, 2016 
42. Zhu X, Xu D, Chen X, et al: Immunomodulatory effects of black chicken peptide on cyclophosphamide-induced immunocompromised mice. Shi Pin Yu Fa Jiao Gong Ye 42: 44-49, 2016.

43. Zak DE, Tam VC and Aderem A: Systems-level analysis of inna-teImmunity. Annu Rev Immunol 32: 547-577, 2014.

44. Leong JW, Sullivan RP and Fehniger TA: microRNA managem-of NK-cell developmental and functional programs. Eur J Immunol 44: 2862-2868, 2014.

45. Seregin SS and Amalfitano A: Improving adenovirus based gene transfer: Strategies to accomplish immune evasion. Viruses 2 : 2013-2036, 2010.

46. Gemperle C, Schmid M, Herova M, Marti-Jaun J, Wuest SJ, Loretz $\mathrm{C}$ and Hersberger M: Regulation of the formyl peptide receptor 1 (FPR1) gene in primary human macrophages. PLoS One 7: 1-6, 2012.

47. Galon J, Costes A, Sanchez-Cabo F, Kirilovsky A, Mlecnik B, Lagorce-Pagès C, Tosolini M, Camus M, Berger A, Wind P, et al: Type, density, and location of immune cells within human colorectal tumors predict clinical outcome. Science 313 1960-1964, 2006.

48. Cortelazzo S, Tarella C, Gianni AM, Ladetto M, Barbui AM, Rossi A, Gritti G, Corradini P, Di Nicola M, Patti C, et al: Randomized trial comparing R-CHOP versus high-dose sequential chemotherapy in high-risk patients with diffuse large B-cell lymphomas. J Clin Oncol 34: 4015-4022, 2016.

49. Wang S, Zheng Q, Tian F, et al: Changes of microRNA expression profiles during NKT cell development. Zhong Guo Mian Yi Xue Za Zhi 33: 979-984, 2017

50. Shaohua S: Research progress in the regulation of SOCS1 on immune response in the body. Chin J Med Officer 35: 1035-1037, 2010.
51. Liu Y: Mechanism of MiR-155 regulating T cell activation. PhD dissertation, Di Er Jun Yi Da Xue. CNKI, Beijing, 2011.

52. Liu Y and Cheng X: Research Progress of MicroRNA on host immunity regulation. Xian Dai Mian Yi Xue 432-435, 2011.

53. Zhang Y, Alexander PB and Wang XF: TGF- $\beta$ family signaling in the control of cell proliferation and survival. Cold Spring Harb Perspect Biol 9: pii: a022145, 2017.

54. Komai T, Okamura T, Yamamoto K and Fujio K: The effects of TGF- $\beta$ s on immune responses. Nihon Rinsho Meneki Gakkai Kaishi 39: 51-58, 2016.

55. Saraiva M and Garra A: The regulation of IL-10 production by immune Cells. Nat Rev Immunol 10: 170-181, 2010.

56. MacNeil IA, Suda T, Moore KW, Mosmann TR and Zlotnik A: IL-10, a novel growth cofactor for mature and immature T cells. J Immunol 145: 4167-4173, 1990.

57. Rutz S and Ouyang W: Regulation of interleukin-10 expression. Adv Exp Med Biol 941: 89-116, 2016.

58. Cao W, Chen W, Liang X, Zhou J, Wei C, Cui S and Liu J: All-trans-retinoic acid ameliorates the inflammation by inducing transforming growth factor beta 1 and interleukin 10 in mouse epididymitis. Am J Reprod Immunol 71: 312-321, 2014

59. Zhang X, Jiang Z, Gu Y, Liu Y, Cao X and Han Y: Inflammation-induced CD69+Kupffer cell feedback inhibits T cell proliferation via membrane-bound TGF- $\beta 1$. Sci China Life Sci 59: 1259-1269, 2016.

60. Ji H, Li Y, Jiang F, Wang X, Zhang J, Shen J and Yang X: Inhibition of transforming growth factor beta/SMAD signal by MiR-155 is involved in arsenic trioxideinduced anti-angiogenesis in prostate cancer. Cancer Sci 105: 1541-1549, 2014. 